\title{
Knowledge and practices of Hygiene of Fresh-Cut Fruit Vendors - A case study of New Juaben Municipality in the Eastern Region of Ghana
}

\author{
Ebenezer Nartey ${ }^{1},{ }^{*}$ John Owusu ${ }^{1}$, Emmanuel Gamor ${ }^{1}$ Eric Edem Mensah ${ }^{2}$ \\ ${ }^{1}$ Koforidua Technical University, Koforidua, Ghana. Faculty of Applied Science and Technology \\ ${ }^{2}$ Accra Technical University, Ghana. School of Applied Science and Technology \\ *jkownsugh@yahoo.com
}

\begin{abstract}
In recent times, many people prefer to purchase fruits which have undergone minimal processing probably due to lack of time and convenience. Fresh-cut fruits are ready-to-eat food, but can be a source of contamination and hence transmission of food-borne diseases such as typhoid and cholera. The contamination of fresh-cut fruits can be caused by the handlers, therefore, this study was carried out to assess the hygienic knowledge and practices of fresh-cut fruit handlers in the New Juaben Municipality in the Eastern Region of Ghana. The handlers studied include those who deal with fruits such as pawpaw, watermelon, and pineapple. The two main instruments used for gathering the data were questionnaires and personal observation. The responses of the handlers were analyzed using SPSS. Most of the respondents work in hygienic premises, have good knowledge of food hygiene, and practice good hygiene especially during packaging of processed fruits. The observation indicated that even though most respondents use gloves and aprons, they do not cover the hair, mouth, and nose, and this could predispose the fruits to contamination. Although, majority of the respondents have waste bins, most $(85.4 \%)$ of them were handoperated with only a few $(7.3 \%)$ having tight cover, and this could invite flies to the premises. Fresh-cut fruit handlers in the New Juaben Municipality should be given periodic education on food hygiene.
\end{abstract}

Keywords: ready-to-eat food, premises, respondents, contamination, food hygiene, minimal processing.

\section{Introduction}

Fruit and vegetable consumption has increased in recent times. This may be due to the possible health benefits associated with their consumption. Fruits and vegetables are a rich source of bioactive substances (Steinmetz \& Potter, 1991) such as vitamins, polyphenols and carotenoids which may have the ability to reduce the risk of cancer, and heart diseases (Kader, 2002). The pressure of work has made it difficult for many people to have much time for preparing food at home, and has thus brought about the need for convenience food. It is therefore common to find people buying food that has been prepared or processed and is ready for consumption. Typical examples of food which are bought ready to be eaten are fruits and vegetables. Fruits and vegetables which are made to go through slight processing are referred to as fresh-cut produce
(IFPA, 2001). Fresh-cut produce are ready-to-eat fruits or vegetables which do not require any further processing before consumption.

Fresh-cut produce are obtained through processes such as sorting, washing, slicing, loading, and packaging by the handler. Hygienic knowledge of the food handler influences his/her attitude towards hygienic practices and hence food safety. Therefore if these processes are not handled properly, the fruit may be predisposed to pathogenic microbial contamination, which can make the food unsafe. Consumption of unsafe food may lead to serious injury or death (James \& Ngarmsak, 2011). Since fresh-cut fruits are consumed without any further processing, when contaminated, will be a health hazard to consumers. It is therefore imperative that the environment where the processing takes place, the people handling the fruits, the equipment involved, and all handling practices involved should 
be hygienic. Salmonella and other pathogenic microorganisms can contaminate fresh produce through sewage, contaminated water or practices of handlers (James \& Ngarmsak, 2011). The consumers of fresh-cut fruits should have the assurance that what they consume is hygienic and free from pathogenic microbial contaminants.

Many authors have studied the microbial safety of many types of cooked ready-to-eat foods with little or no attention to fresh-cut fruits (Clarence et al., 2009; Yeboah-Manu et al., 2010; Isara et al., 2010; Wogu et al., 2011; Ackah et al., 2011; Yadav et al., 2011; Feglo and Sakyi, 2012). The present study was therefore undertaken to assess the hygienic knowledge of fresh-cut fruit handlers and to determine how this knowledge influences their handling practices and the safety of fruits sold.

\section{Methodology}

\subsection{Research design}

The study adopted quantitative research design to explore personal hygiene behaviour of handlers, hygiene of equipment and premises, handling practices, packaging and storage practices of freshcut fruit vendors.

\subsection{Target respondents}

The study used fresh-cut fruit handlers who handle fruits such as pawpaw, watermelon, and pineapple from the Koforidua Municipality in the Eastern Region of Ghana.

\subsection{Sources of data and data collection instruments}

Primary and secondary sources of data were employed for the study. The instruments used to collect the primary data were questionnaires and an on-site observation guide, but the secondary data were obtained from journals, reports and textbooks related to the study.

\subsection{Sampling and sampling techniques}

Purposive sampling was used to select nine (9) initial vendors whiles the remaining thirty-two (32) were obtained through snowballing. The sample consisted of fourty-one (41) fruit vendors in ten (10) suburbs in the Koforidua municipality namely 'Adweso, Srodae, Betom, Old estate, Koforidua Polytechnic Campus,
205, Two Streams, Nsukwao, Anlo Town and Kwakyea.

\subsection{Informed consent and assurance of anonymity}

Informed consent was sought from all the vendors before the data collection exercise begun. The consent highlighted issues such as assurance of anonymity, respect of respondents and their views, treatment of sensitive issues, opportunity to back out of the study at any time without fear of intimidation.

\subsection{Data analysis and presentation}

The collated data were analyzed quantitatively with the aid of the Statistical Package for Social Scientists (SPSS) Version 16.0. The means and percentages obtained were presented in tables and in figures.

\section{Results and Discussions}

\subsection{Demographic information}

In all forty-one (41) respondents were used for the study, and $95.1 \%$ of them were females (Table 1). The results are in agreement with other previous studies where majority of food vendors were found to be females (Martins \& Com, 2006;Chukuezi, 2010). Majority of the respondents were over 20 years of age, and this shows that they are adults who can provide reasonable responses to the questionnaires sent to them. The results also indicated that while $17.1 \%$ of the respondents had no formal education, majority of them $(82.9 \%)$ have had formal education ranging from primary to tertiary. Chukuezi (2010) found that $14.3 \%$ of respondents did not have any formal education, and this is similar to the present study. Education can influence a person's attitude, and therefore it was expected that with a high percentage of respondents having some level of education, fresh-cut fruits will be handled well. In terms of their marital status, most of them $(56.1 \%)$ were unmarried. 
Table 1

Demographic information of fresh-cut fruit handlers

\begin{tabular}{|c|c|c|}
\hline Variables & Frequency & Percentage $(\%)$ \\
\hline \multicolumn{3}{|l|}{ Gender } \\
\hline Male & 2 & 4.9 \\
\hline Female & 69 & 95.1 \\
\hline Total & 41 & 100 \\
\hline \multicolumn{3}{|l|}{ Age (Years) } \\
\hline Below 20 & 5 & 12.2 \\
\hline $21-30$ & 12 & 29.3 \\
\hline $31-40$ & 10 & 24.4 \\
\hline 41 and Above & 14 & 34.1 \\
\hline Total & 41 & 100 \\
\hline \multicolumn{3}{|l|}{ Education } \\
\hline No formal education & 7 & 17.1 \\
\hline Primary & 23 & 56.1 \\
\hline Secondary & 9 & 22 \\
\hline Tertiary & 2 & 4.9 \\
\hline Total & 41 & 100 \\
\hline \multicolumn{3}{|l|}{ Marital Status } \\
\hline Single & 23 & 56.1 \\
\hline Married & 15 & 36.6 \\
\hline Divorced & 3 & 7.3 \\
\hline Total & 41 & 100 \\
\hline \multicolumn{3}{|l|}{ Health Certificate } \\
\hline Yes & 13 & 31.7 \\
\hline No & 28 & 68.3 \\
\hline Total & 41 & 100 \\
\hline \multicolumn{3}{|c|}{ Where health certificate was obtained } \\
\hline Municipal Assembly & 13 & 31.7 \\
\hline Not applicable (No certificate) & 28 & 68.3 \\
\hline Total & 41 & 100 \\
\hline \multicolumn{3}{|l|}{ How old is the health certificate } \\
\hline Below six (6) months & 2 & 15.4 \\
\hline Exactly six (6) months & 2 & 15.4 \\
\hline Seven (7) months - one (1) year & 5 & 38.5 \\
\hline More than one (1) year & 4 & 30.7 \\
\hline Not applicable & 28 & - \\
\hline Total & 41 & 100 \\
\hline
\end{tabular}

\subsection{Health certificate}

It is important that people involved in food preparation and sales are monitored to know whether they do so hygienically or not so that the right measures could be taken to ensure that they do not put the life of the consumer at risk. When the vendor is examined medically his/her health status could be ascertained and health certificate issued where the person does not carry infectious diseases which can be transmitted to consumers. Most respondents $(68.3 \%)$ indicated that they do not possess health certificate (Table 1). The results are similar to the one where most respondents were found to have no health certificate (Isara et al., 2010; Ackah et al., 2011). Even though they did not have health certificates, they were handling fresh-cut fruits, and if they have any infectious diseases, these could be transferred to consumers. This is an indication of the laxity in the enforcement of the law. For those who had the certificates, the study revealed that they were issued by the Koforidua Municipal Assembly. Respondents whose health certificates were issued more than 1 year ago were $30.7 \%$. In Ghana, the 
health certificate has a validity period of one year. However, some fresh-cut fruit handlers had health certificates which had gone beyond this validity period.

\subsection{Personal bygiene of fresh-cut fruit handlers}

Table 2

Personal hygiene of fresh-cut fruit handlers

\begin{tabular}{|c|c|c|c|}
\hline Question & & Frequency & Percentage $(\%)$ \\
\hline \multicolumn{4}{|c|}{ Number of times bathing in a day } \\
\hline Once a day & & 25 & 61.0 \\
\hline Twice a day & & 16 & 39.0 \\
\hline \multirow[t]{2}{*}{ None } & & 0 & 0 \\
\hline & Total & 41 & 100 \\
\hline \multicolumn{4}{|c|}{ Hand washing prior to fruit handling } \\
\hline Yes & & 23 & 56.1 \\
\hline \multirow[t]{2}{*}{ No } & & 18 & 43.9 \\
\hline & Total & 41 & 100 \\
\hline \multicolumn{4}{|l|}{ How hands are washed } \\
\hline Cold water & & 8 & 19.5 \\
\hline Cold soapy water and rinsing & & 15 & 36.6 \\
\hline \multirow[t]{2}{*}{ Not applicable } & & 18 & 43.9 \\
\hline & Total & 41 & 100 \\
\hline \multicolumn{4}{|c|}{ Hands washing after visiting toilet } \\
\hline Yes & & 41 & 100 \\
\hline \multirow[t]{2}{*}{ No } & & 0 & 0 \\
\hline & Total & 41 & 100 \\
\hline \multicolumn{4}{|c|}{ Hands washing after visiting toilet } \\
\hline With cold water & & 6 & 14.6 \\
\hline \multirow[t]{2}{*}{ With cold water and soap } & & 35 & 85.4 \\
\hline & Total & 41 & 100 \\
\hline
\end{tabular}

Food is handled by human beings, and as such they are the main agents of food contamination. Therefore the body should be washed to reduce the microbial load to acceptable levels to prevent food contamination. Majority $(61.0 \%)$ of the respondents said that they bath once in a day with the rest $(39.0 \%)$ bathing twice a day (Table 2). This will prevent the transfer of germs onto clothes and then onto food (Foskett et al., 2003), and in addition give them pleasant smell. A greater number of respondents $(56.1 \%)$ indicated that they wash their hands before handling the fruits. The hand is the main part of the body which transfers microorganisms from various parts of the body into food (FAO, 1995), so it is important that it is washed before handling food. A substantial number (43.9\%), on the other hand, indicated that they do not wash their hands before handling the fruits. This act could easily transfer pathogens on their hands into the fresh-cut fruit. In other studies it was revealed that $47.5 \%$ do not wash their hands before handling food (Muoki et al., 2008). Out of the number who wash their hands, $34.8 \%$ of them use only cold water, and obviously this is not enough to kill the pathogens on their hands. The study also found out that all the respondents wash their hands after visiting the toilet, and this practice is in agreement with a previous study (Martins \& Com, 2006), but even that $14.6 \%$ of them do so with cold water. Proper hand washing after using the toilet has the tendency to prevent food-borne diseases like typhoid (WHO, 2003), and the use of hot water and bactericidal soap is the best way of hand washing (Foskett et al., 2003). Observation carried out indicated that most respondents $(75.6 \%)$ had short fingernails, and this is similar to the results of some previous studies (Muinde \& Kuria, 2005; Muoki et al., 2008). Also 56.1\% had clean fingernails and $43.9 \%$ had dirty fingernails (Table 3). Dirty 
fingernails can transfer bacteria into food to cause contamination (Foskett et al., 2003). Only 9.8\% of the respondents wore hair cover. This is serious because the hair and dandruff can drop into the fresh-cut fruit to cause especially Staphylococcus aureus contamination (Gaman \& Sherrington, 1996). Similar results were reported in some previous studies (Muinde and Kuria, 2005; Chukuezi, 2010). None of the respondents wore any mouth or nose cover
(Table 3). Thus, whenever they sneeze or cough, germs specifically Staphylococcus aureus is most likely transferred onto the fresh-cut fruit (Gaman and Sherrington, 1996). Majority of the respondents $(70.7 \%)$ wore aprons to cover their clothes as this act can helps prevent contaminants in their clothes from transferring into the cut-fruit. The results are in agreement with a similar one where $69.2 \%$ of respondents wore aprons (Cuprasitrut et al., 2011).

Table 3

Observation on personal hygiene and use of protective clothing

\begin{tabular}{lcccc}
\hline \multicolumn{1}{c}{ Observation } & Yes & $(\%)$ & No & $(\%)$ \\
\hline Short finger nails & 31 & 75.6 & 10 & 24.4 \\
Clean finger nails & 23 & 56.1 & 18 & 43.9 \\
Use of hair cover & 4 & 9.8 & 37 & 90.2 \\
Use of mouth cover & - & 0.0 & 41 & 100 \\
Use of nose cover & - & 0.0 & 41 & 100 \\
Use of gloves & 21 & 51.2 & 20 & 48.8 \\
Use of apron & 29 & 70.7 & 12 & 29.3 \\
\hline
\end{tabular}

\subsection{Hygiene of premises of fresh-cut fruit handlers}

Even though the observation made showed that most $(90.2 \%)$ of the premises where the fresh fruits are cut are not enclosed, flies were observed in only a few of these premises $(31.7 \%$ ) (Table 4). This is however serious because flies can transmit diseases such as typhoid and cholera. Most of the premises
(53.7\%) had cemented floors, and most $(58.5 \%)$ were found to be clean. The present results are consistent with those reported earlier where most food vendors had clean environment (Chukuezi, 2010). A clean environment discourages food pests such as flies from coming into food premises (Foskett et al., 2003).

Table 4

Observation on cleanliness and hygiene of premises

\begin{tabular}{lcccc}
\hline Observation & Yes & $(\%)$ & No & $(\%)$ \\
\hline Cleanliness of premises & 24 & 58.5 & 17 & 41.5 \\
Premises enclosed & 4 & 9.8 & 37 & 90.2 \\
Flies on premises & 13 & 31.7 & 28 & 68.3 \\
Bareness of floor & 19 & 46.3 & 22 & 53.7 \\
\hline
\end{tabular}


3.5 Handling of unpeeled fruits and the packeaged fresh-cut fruits

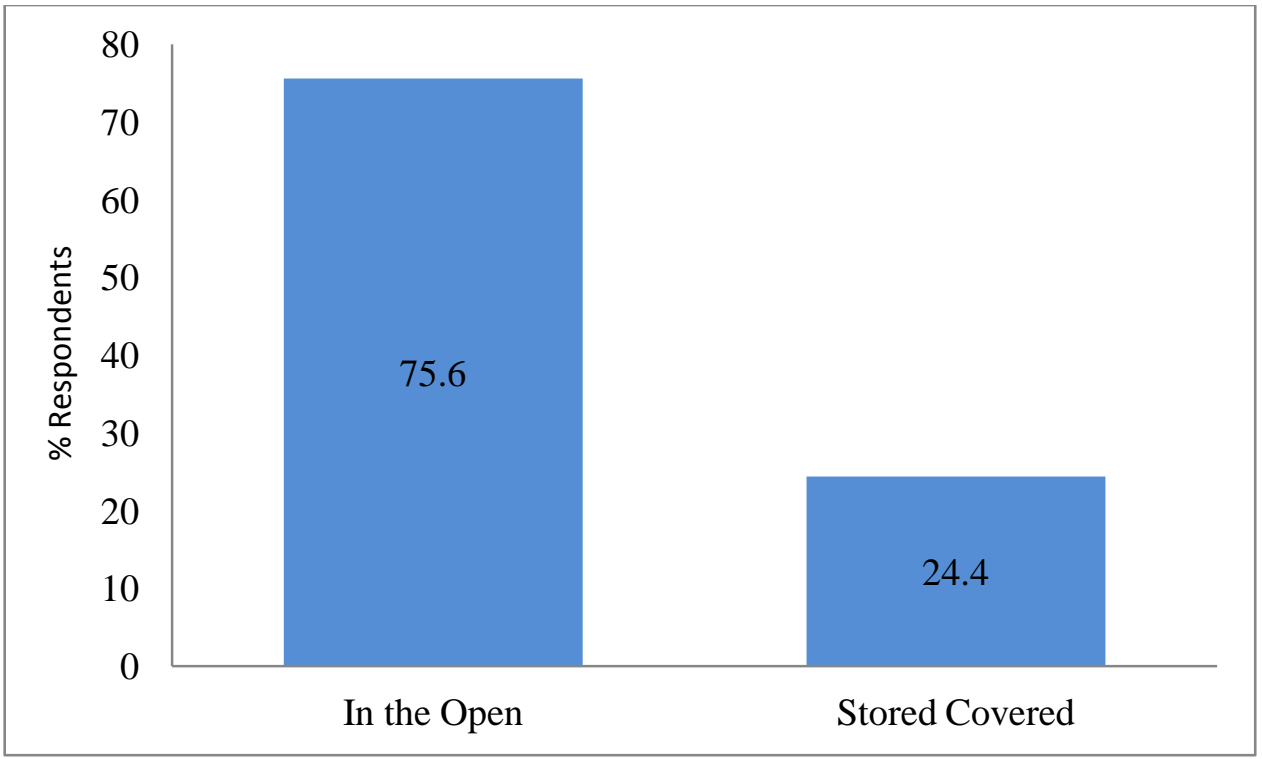

Fig. 1: Storage of unpeeled fruits

The handling of the unpeeled fruits and fresh-cut fruits can influence the hygiene of the food. The study revealed that most respondents $(75.6 \%)$ store the unpeeled fruits in the open while the rest cover them (Fig.1). Fruits in the open can be contaminated by dust and flies. The results also showed that majority of the respondents $(56.0 \%)$ wash their hands before peeling the fruits while the rest do not (Fig. 2).

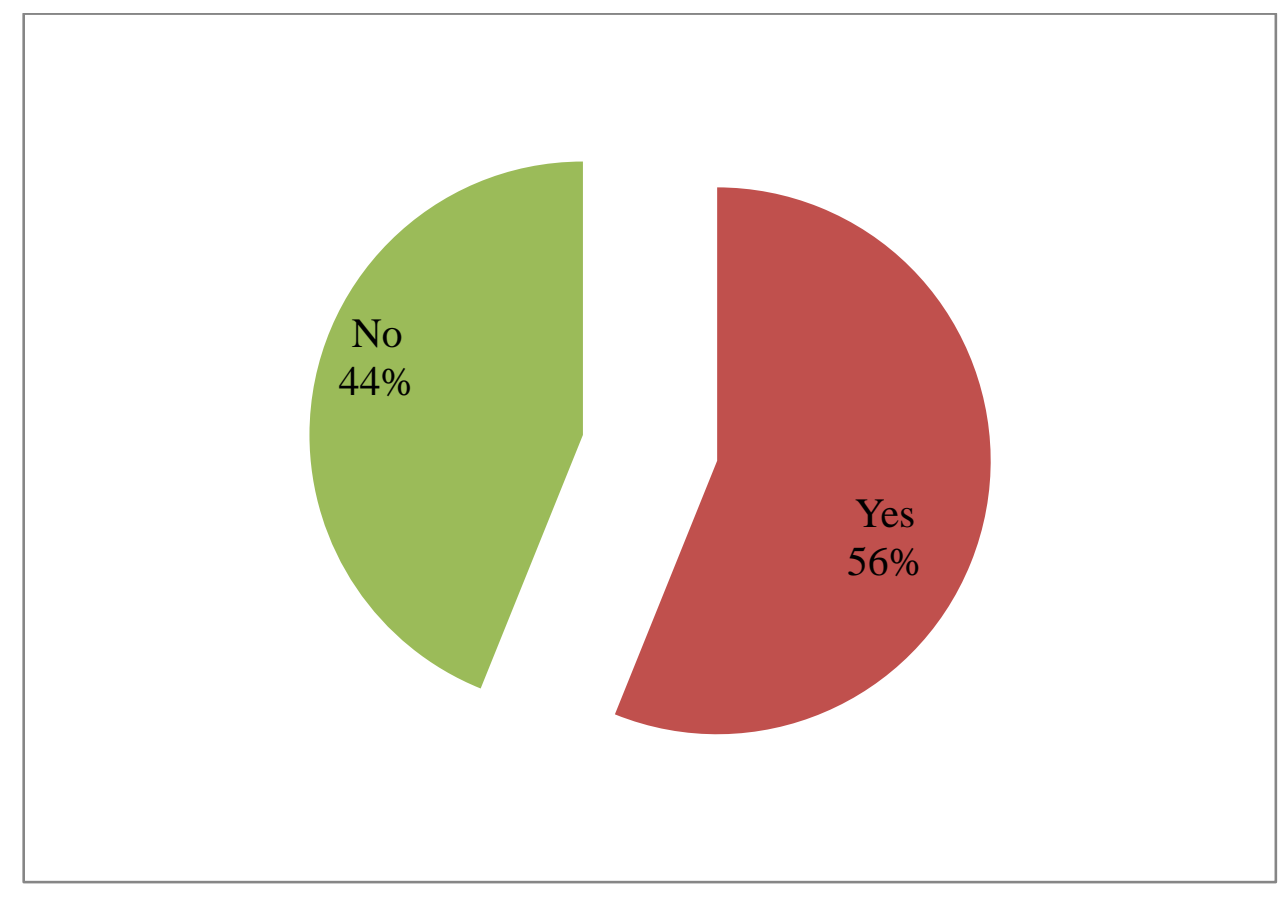

Fig. 2: Washing of hands prior to peeling of fruits

All those who wash their hands said they wash with only cold water. Washing the hands with cold water alone is not enough to kill the pathogens on their hands, and therefore this is a poor hygienic practice.
They should rather use hot water and soap for washing before rinsing thoroughly with clean water. In this study, it was revealed that most of the respondents $(95.1 \%)$ do not lick their fingers to 
separate wrappers for the fresh-cut fruit. This is a good hygiene practice which could enhance the hygiene and safety of the fruit. All respondents do not blow air to separate the wrappers. This is another good hygienic practice. The results are better than what Chukuezi (2010) reported in his study where $28.57 \%$ respondents blew air into polythene bag during food service. Majority of the respondents $(85.4 \%)$ do not use their bare hands to pick the fruits during packaging but they use the wrapper as gloves (Table 5), and this can prevent the contamination of the fresh-cut fruit (Foskett et al., 2003). However, for the minority who use their bare hands (14.6\%), they wash their hands with cold water. In a related research $47.62 \%$ of the respondents handled food with bare hands (Chukuezi, 2010). Most respondents $(97.6 \%)$ said that the packaged fresh-cut fruits are stored in bowls but only a few $(2.4 \%)$ indicated that they store them in an ice chest with ice blocks (Fig. 3). Storage in ice chest with ice block can help to inactivate enzymes to reduce microbial growth, and to reduce deterioration of the fresh-cut fruit (Gaman and Sherrington, 1996).

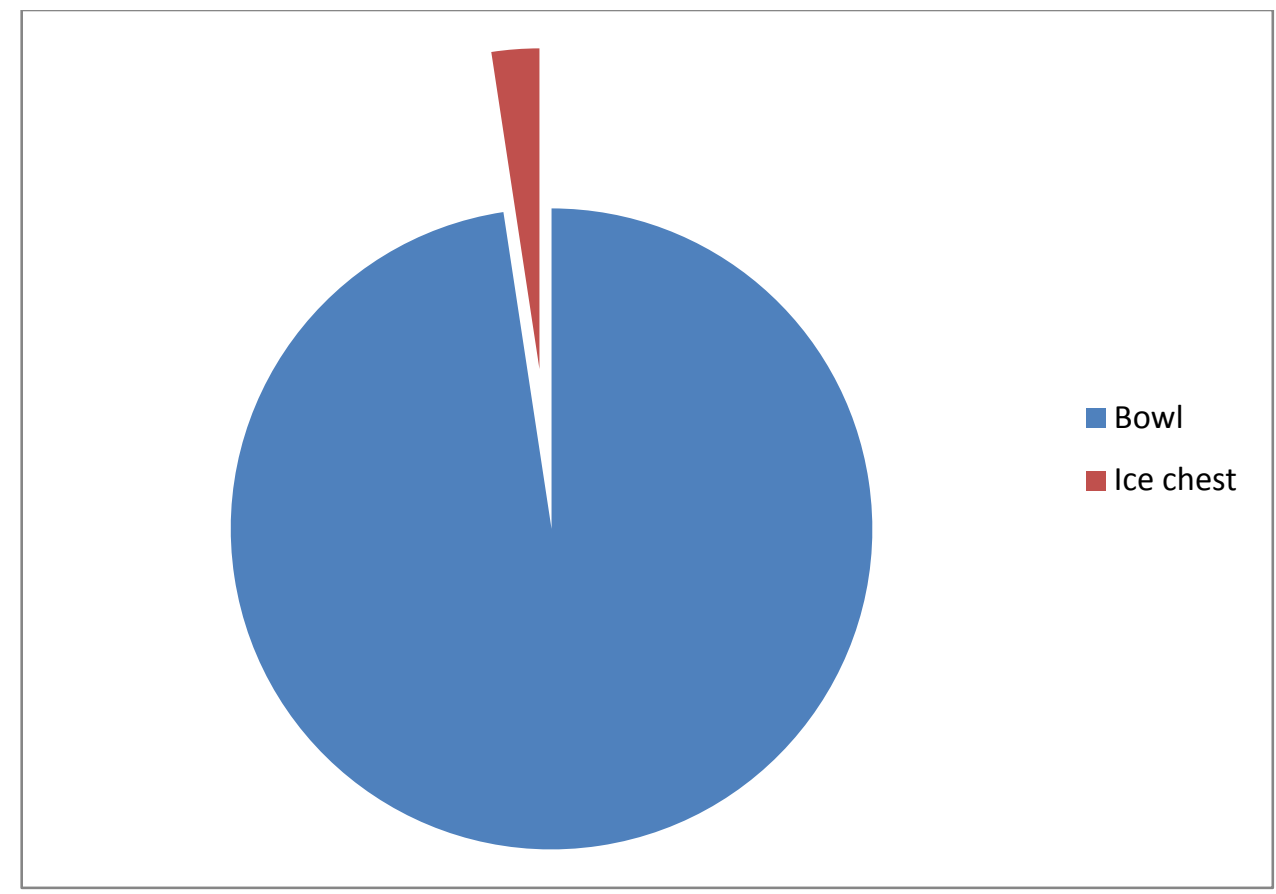

Fig. 3: Storage of packaged fruits

\subsection{Hygiene of processing equipment of fresh-cut fruit handlers}

The results on washing of bowls are shown in Table 6. Most respondents $(61.0 \%)$ wash their bowls with cold soapy water and rinse afterwards with cold water, but only $4.9 \%$ use hot soapy water for washing bowls and rinse afterwards. This is the best practice of all. Similar outcomes were reported by a previous author (Chukuezi, 2010). In terms of washing of knives most respondents (46.3\%) use cold soapy water whereas only $2.4 \%$ use hot soapy water. Hot soapy water is the best option which can kill most of the pathogens on the knives and in the bowls (Foskett et al., 2003). However, this is the method which is adopted by a smaller percentage of the respondents. The frequency of washing of napkins of the fresh-cut fruit handlers is shown in Table 6. Most respondents $(56.1 \%)$ wash their napkins once a day whiles only $2.4 \%$ wash as soon as dirty.

Table 5

Hygiene during packaging and storage of fruits

\begin{tabular}{lll}
\hline Question & Frequency & Percentage $(\%)$ \\
\hline Finger licking to separate wrappers & & \\
Yes & 2 & 4.9 \\
\hline
\end{tabular}




\begin{tabular}{|c|c|c|c|}
\hline \multirow[t]{2}{*}{ No } & & 39 & 95.1 \\
\hline & Total & 41 & 100 \\
\hline \multicolumn{4}{|c|}{ Air blowing to separate wrappers } \\
\hline Yes & & 0 & 0.0 \\
\hline \multirow[t]{2}{*}{ No } & & 41 & 0.0 \\
\hline & Total & 100 & 100 \\
\hline \multicolumn{4}{|c|}{ Picking fruits with bare hands } \\
\hline Yes & & 6 & 14.6 \\
\hline \multirow[t]{2}{*}{ No } & & 35 & 85.4 \\
\hline & Total & 41 & 100 \\
\hline \multicolumn{4}{|c|}{ If Yes are hands washed } \\
\hline Yes & & 6 & 21.9 \\
\hline No & & 0 & 0 \\
\hline \multirow[t]{2}{*}{ Not applicable } & & 35 & 78.1 \\
\hline & Total & 41 & 100 \\
\hline \multicolumn{4}{|c|}{ How hands are washed } \\
\hline With cold water & & 6 & 14.6 \\
\hline \multirow{2}{*}{ Not applicable } & & 35 & 85.4 \\
\hline & Total & & \\
\hline \multicolumn{4}{|c|}{ Use of gloves for packaging } \\
\hline Yes & & 36 & 87.8 \\
\hline \multirow[t]{2}{*}{ No } & & 5 & 12.2 \\
\hline & Total & 41 & 100 \\
\hline
\end{tabular}

Table 6:

Hygiene processing equipment fresh-cut fruits

\begin{tabular}{|c|c|c|c|}
\hline Question & & Frequency & Percentage $(\%)$ \\
\hline \multicolumn{4}{|l|}{ Washing of bowls } \\
\hline Cold water & & 8 & 19.5 \\
\hline Cold soapy water and rinsing & & 25 & 61.0 \\
\hline Hot water & & 6 & 14.6 \\
\hline Hot soapy water and rinsing & & 2 & 4.9 \\
\hline & Total & 41 & 100 \\
\hline \multicolumn{4}{|l|}{ Washing of knives } \\
\hline Cold water & & 17 & 41.5 \\
\hline Cold soapy water and rinsing & & 19 & 46.3 \\
\hline Hot water & & 4 & 9.8 \\
\hline Hot soapy water and rinsing & & 1 & 2.4 \\
\hline & Total & 41 & 100 \\
\hline \multicolumn{4}{|l|}{ Washing of napkins } \\
\hline Once a day & & 23 & 56.1 \\
\hline Twice a day & & 3 & 7.3 \\
\hline Thrice a day & & 3 & 7.3 \\
\hline Weekly & & 11 & 26.9 \\
\hline As soon as dirty & & 1 & 2.4 \\
\hline & Total & 41 & 100 \\
\hline
\end{tabular}

should be handled well. The study found out that

\subsection{Handling of waste of fresh-cut fruit handlers}

Food waste is an important source of contamination (Gaman \& Sherrington, 1996), therefore waste majority of the respondents $(87.8 \%)$ had waste bins (Table 7), and is consistent with other previous studies (Chukuezi, 2010; Cuprasitrut et al., 2011), but only $34.1 \%$ of them were covered. It has been 
reported that only $7.7 \%$ of waste bins were covered in a study (Cuprasitrut et al., 2011). Out of those with covers, only $7.3 \%$ had complete coverage. Thus the remaining $26.8 \%$ of the bins were covered partially. This could easily attract food pest into the premises to cause contamination of the fruits (Gaman and Sherrington, 1996). Majority of the waste bins $(85.4 \%)$ were hand-operated, and this can encourage food contamination. Therefore pedal-operated bins are much preferred (Gaman \& Sherrington, 1996).

Table 7

Observation on waste handling

\begin{tabular}{lccccccc}
\hline Observation & Yes & $(\%)$ & No & $(\%)$ & \multicolumn{2}{c}{ Not Applicable } \\
\cline { 5 - 7 } & & & & & Yes & No & $(\%)$ \\
\hline Presence of waste bin & 36 & 87.8 & 5 & 12.2 & - & - & - \\
Waste bin covered & 14 & 34.1 & 22 & 53.7 & - & - & 65.9 \\
Waste bin coverage completely & 3 & 7.3 & 11 & 26.8 & 27 & - & -12.2 \\
Waste bin hand operated & 35 & 85.4 & 1 & 2.4 & 5 & - & \\
\hline
\end{tabular}

\section{Conclusion}

The study indicated that majority of the respondents have formal education, and this might have influenced their hygienic knowledge. Most of them practiced good hygiene especially during packaging of fresh-cut fruits. However, they exhibited poor waste handling practices, therefore they need to be given some training to improve upon their level of hygienic knowledge.

\section{References}

Ackah, M., Gyamfi, E. T., Anim, A. K, Osei, J., Hansen, J. K., and Agyemang, O. (2011). Socio-economic profile, knowledge of hygiene and food safety practices among street-food vendors in some parts of Accra-Ghana. Internet Journal of Food Safety. 13: 191-197.

Chukuezi, C. O. (2010). Food Safety and Hygienic Practices of Street Food Vendors in Owerri, Nigeria. Studies in Sociology of Science.1 (1): 50-57.

Clarence, S. Y., Obinna, C. N., Shalom, N. C. (2009). Assessment of bacteriological quality of ready to eat food (meat pie) in Benin City Metropolis, Nigeria. African Journal of Microbiology Research. 3 (6): 390-395.

Cuprasitrut, T., Srisorrachatr, S., and Malai, D. (2011). Food safety knowledge, attitude and practice of food handlers and microbiological and chemical food quality assessment of food for making merit for monks in Ratchathewi
District, Bangkok. Asia Journal of Public Health. 2 (1): 27-34.

FAO (1995). Codex Alimentarious. General requirements (food hygiene) FAO, Rome, 1995. 188-192.

Feglo, P., and Sakyi, K. (2012). Bacterial contaminatrion of street vending food in Kumasi, Ghana. Journal of Medical and Biomedical Sciences. 1 (1): 1-8.

Foskett, D., Ceserani, V., and Kinton, R. (2003). The theory of catering. 10th ed. Hodder and Stoughton, Italy.

Gaman, P. M., and Sherrington, K. B. (1996). The science of food. 4th ed. Bath Press, Great Britain.

Isara, A. R., Isah, E. C., Lofor, P. V. O., and Ojide, C. K. (2010). Food contamination in fast food restaurants in Benin City, Edo State, Nigeria: Implications for food hygiene and safety. Public Health. 124: 467-471.

James, J. B., and Ngarmsak, T. (2011). Processing of fresh-cut tropical fruits and vegetables: A technical guide. Food and Agriculture Organization of the United Nations Regional Office for Asia and the Pacific, Bangkok. Thailand.

Martins, J. H., and Com, D. (2006). Socio-economic and hygiene features of street food vending in Gauteng. SAJCN. 19 (1): 18-25.

Muinde, O. K., and Kuria, E. (2005). African Journal of Food Agriculture Nutrition and Development. 5 (1): 1-14. 
Muoki, M. A.., Tumuti, D. S., and Rombo, G. O. (2008).Nutrition and public hygiene among children underfive years of age in Mukuru slums of Makadaradivision, Nairobi. East African Medical Journal. 85 (8): 386-397.

Steinmetz, K. A., Potter, J. D. 1991. Cancer causes control. American Journal of Medicine, 2 (6), 427442.

Wogu, M. D., Omoruyi, M. I., Odeh, H. O., and Guobadia, J. N. (2011). Microbial load in ready-to-eat rice sold in Benin City. Journal of Microbiology and Antimicrobials. 3 (2): 29-33.
World Health Organisation (2003). Global Database onChild Growth and Malnutrition.

Yadav, N., Saini, P., Kaur, D., Srivastava, N., and Pandey, D. (2011). Microbial quality and safety of ready to serve street foods vended in Allahabad City, India. Internet Journal of Food Safety. 13: 6-10.

Yeboah-Manu, D., Kpeli, G., Akyeh, M., and Bimi, L. (2010). Bacteriological quality of ready-to-eat foods sold on and around University of Ghana Campus. Research Journal of Microbiology. 5 (2): 130-136. 